\title{
Circadian rhythm of blood pressure in patients dependent on ventricular demand pacemakers
}

\author{
ANTHONY B DAVIES, BRIAN A GOULD, PETER M M CASHMAN, EDWARD B RAFTERY \\ From the Department of Cardiology and the Divisions of Clinical Science and Bioengineering, Northwick Park \\ Hospital and Clinical Research Centre, Harrow, Middlesex
}

SUMMARY The reported circadian rhythm of blood pressure variability with a rise in pressure before awakening has been the subject of controversy. Previous studies have suggested that since heart rate continues to fall before awakening while blood pressure is rising these physiological variables are subject to different control mechanisms. To evaluate further the dissociation of heart rate and blood pressure changes in a group of patients with a fixed heart rate, 11 patients who were dependent on ventricular demand pacemakers underwent intra-arterial ambulatory blood pressure monitoring. Nine aged matched control subjects followed the same protocol. Circadian curves plotted from pooled hourly mean data showed that despite a fixed heart rate the circadian pattern persisted, although attenuated, with blood pressure rising several hours before its rapid rise on awakening. Physiological testing showed that despite a fixed heart rate systolic blood pressure rose in response to bicycle exercise, there was a postural fall in the blood pressure on tilting and a modified Valsalva response. There was considerable beat to beat variability resulting presumably from asychronous pacing. Hour to hour changes did not contribute to the differences between the two groups and were not responsible for attenuation of the circadian rhythm. It is concluded that blood pressure and heart rate control mechanisms may be dissociated, particularly in the period before awakening.

Intra-arterial ambulatory monitoring has clearly shown the variable nature of the blood pressure, although this has proved difficult to quantify. ${ }^{1}$ Millar-Craig $e t a l^{2}$ reported a circadian rhythm of blood pressure in which the highest peak occurred in the morning falling gradually during the day and a second peak in the early evening falling to a nadir at 0300 hours. After this nadir the blood pressure rises gradually until the time of awakening, when there is a rapid rise related to arousal. Interestingly, the mean heart rate continues to fall until the time of awakening. This dissociation of heart rate and blood pressure has suggested separate regulatory control mechanisms for blood pressure and heart rate. These data have been the subject of controversy, ${ }^{3}$ which we have sought to resolve by studying patients with a fixed heart rate produced by ventricular pacemakers. In addition, this study provided an opportunity to study blood pressure variability in patients without heart rate variability.

Requests for reprints to Dr E B Raftery, Northwick Park Hospital \& Clinical Research Centre, Watford Road, Harrow, Middlesex HA1 $3 \mathrm{UJ}$.

Accepted for publication 2 February 1984

\section{Patients and methods}

A group of 11 patients aged 52-83 years who had been treated for symptomatic idiopathic complete heart block by implantation of a ventricular demand pacemaker was studied. All patients were known to be dependent on pacemakers, and normal function was confirmed by at least two 24 hour continuous electrocardiographic recordings, which also confirmed the absence of other arrhythmias. Before study, all patients gave their informed written consent, and the project was approved by the hospital ethical committee. A second group of nine age and sex matched control subjects who had uncomplicated hypertension was selected from the department records.

A Teflon cannula was inserted into the nondominant brachial artery under local anaesthesia, ${ }^{4}$ and blood pressure was recorded on tape cassettes using a transducer-perfusion unit linked to an Oxford Medilog Mark I tape recorder. ${ }^{5}$ Calibration was performed at repeated intervals during the study, requiring the patient to return to the hospital for short periods at the beginning and end of the day: otherwise 
the patients were encouraged to undertake their normal activities. After insertion of the arterial cannula the patients underwent physiological testing before ambulatory monitoring outside hospital for a full 24 hours.

Apart from minor local bruising no complications resulted from arterial cannulation, despite the advanced age of the patients. One test had to be repeated because of intermittent kinking of the pressure line.

\section{PHYSIOLOGICAL TESTING}

All the patients were rested supine on a horizontal tilt table for 15 minutes in a quiet darkened room before the physiological exercises to establish baseline systolic and diastolic blood pressures. At the end of the rest period the patients were warned and the table was rapidly tilted to $60^{\circ}$ and maintained at that inclination for five minutes, after which it was returned to the horizontal position. The patients were then placed in a semirecumbent position ( $45^{\circ}$ head up), and carotid sinus massage was performed for five seconds on each carotid artery. A formal Valsalva manoeuvre $(40 \mathrm{~mm}$ $\mathrm{Hg}$ ) was then carried out for 10 seconds, and finally
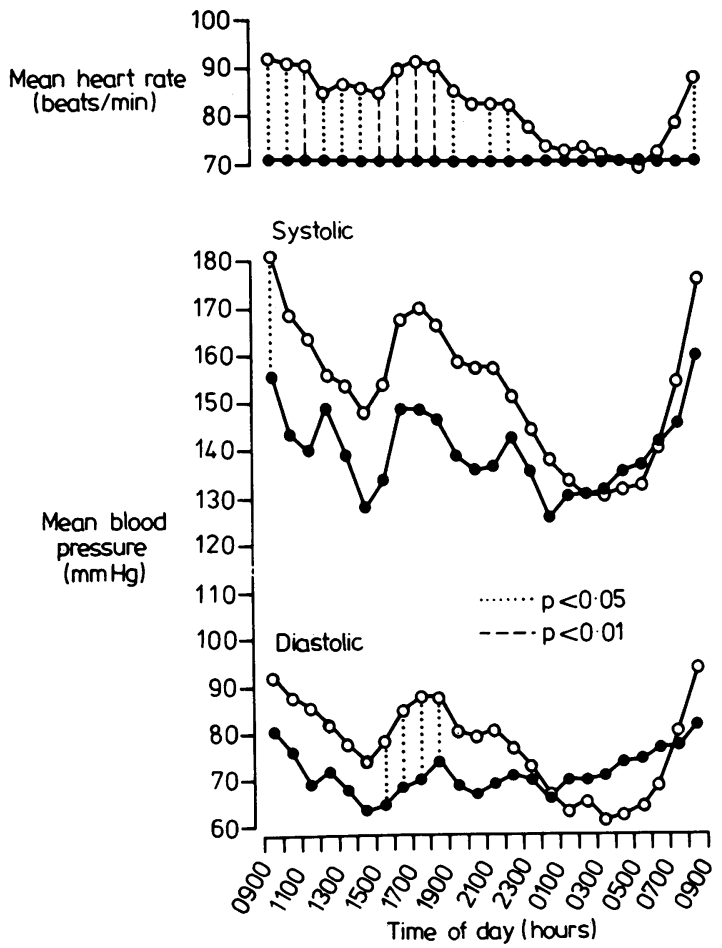

Fig. 1 Circadian rhythm of mean blood pressure and heart rate in nine paced patients $(\bullet)$ and nine age matched control subjects (O). the patient performed maximal (symptom limited) exercise on a cycle ergometer (three minute stages of 200,400 , and $700 \mathrm{kpm} / \mathrm{min}(32.7,65.4$, and 114.4 W)).

\section{DATA ANALYSIS}

Data analysis was performed using a computer which allowed beat by beat extraction of systolic and diastolic blood pressures and heart rate. ${ }^{6}$ The hourly mean systolic and diastolic blood pressures and heart rates were calculated, and circadian trend plots drawn (Fig. 1) as described.2 The results were then subjected to statistical analysis to assess short term and long term variability.

Short term variability was quantified by generating distributions of beat to beat differences in blood pressure and pulse interval (from which heart rate was derived) over periods of one hour. Every such distribution had a mean very close to zero, but other measures such as the variance are a sensitive measure of beat to beat irregularities, however short lived.

Long term variability was analysed using two methods. ${ }^{1}$ The first was defined as the standard deviation of the 24 hourly mean values. Because this index does not in itself provide information about hour to hour changes and hence cannot discriminate between a smooth curve and a jagged curve of similar amplitude, a second index was defined as the mean magnitude of the 24 hour to hour changes irrespective of direction. The Mann-Whitney $U$ test was used to compare the values of these indices in the two groups.

The results from nine of these patients were compared with those of age and sex matched subjects with hypertension whose mean (SEM) clinic pressures were $186(7) \mathrm{mm} \mathrm{Hg}$ systolic and $109(2) \mathrm{mm} \mathrm{Hg}$ diastolic.

For analysis of the physiological testing, calibration and arterial waveforms were printed out using a high speed fibreoptic recorder. Systolic and diastolic pressures were derived using a purpose built chart digitiser linked to a microcomputer with reference to the standard calibration markings.

\section{Results}

\section{AMBULANT RECORDINGS}

The $24 \mathrm{~h}$ trend plot (Fig. 1) showed the same diurnal pattern of blood pressure for both pacemaker patients and age matched control subjects, although the curves for the former appeared attenuated. The plot of mean pressure for the paced group reached a nadir at 0100 , two hours earlier than for the control group. The pressures then rose gradually with an increased rate of systolic pressure rise after arousal at about $0700 . .^{78}$ The amplitude of the circadian pattern was less in the paced group than in the hypertensive group. 
Table Standard deviation of mean hourly blood pressures and mean magnitude of hour to hour change in value $(\mathrm{mm} \mathrm{Hg})$ in paced patients and control subjects

\begin{tabular}{|c|c|c|c|c|}
\hline & \multicolumn{2}{|c|}{ Systolic pressures } & \multicolumn{2}{|c|}{ Diastolic pressures } \\
\hline & Paced & Control & Paced & Control \\
\hline $\begin{array}{l}\text { Mean } \\
\text { p }\end{array}$ & $\begin{array}{r}7.7 \\
21.6 \\
13.3 \\
19.4 \\
17.0 \\
16.0 \\
9.3 \\
19.0 \\
10.7 \\
149 \\
<0\end{array}$ & $\begin{array}{c}\text { Hourby va } \\
24.4 \\
13.4 \\
13.7 \\
21.4 \\
17.8 \\
23.5 \\
23.9 \\
21.9 \\
23.3 \\
20.3\end{array}$ & $\begin{array}{r}\mathbf{n}=9 \text { ) } \\
7.7 \\
10.6 \\
4.9 \\
9.4 \\
15.7 \\
11.0 \\
6.2 \\
7.6 \\
8.3 \\
9.0\end{array}$ & $\begin{array}{r}13.6 \\
6.9 \\
11.6 \\
11.4 \\
12.2 \\
15.7 \\
15.4 \\
17.0 \\
15.4 \\
13.2\end{array}$ \\
\hline $\begin{array}{l}\text { Mean } \\
\text { p }\end{array}$ & $\begin{array}{r}7.2 \\
12.5 \\
12.6 \\
11.3 \\
8.1 \\
13.4 \\
8.3 \\
13.1 \\
6.4 \\
10.3\end{array}$ & $\begin{array}{c}\text { to hour } \\
12.7 \\
6.6 \\
11.2 \\
9.0 \\
9.8 \\
12.6 \\
10.6 \\
142 \\
16.4 \\
11.4\end{array}$ & $\begin{array}{l}g e(n=9) \\
3.7 \\
7.3 \\
5.0 \\
5.1 \\
5.2 \\
6.2 \\
4.3 \\
6.1 \\
3.1 \\
5.1\end{array}$ & $\begin{array}{r}7 \cdot 1 \\
4.9 \\
8.0 \\
4.2 \\
6.0 \\
8.2 \\
7.5 \\
12.5 \\
10.2 \\
7.6\end{array}$ \\
\hline
\end{tabular}

^Mann-Whitney U test.

The standard deviations of hourly means (Table) showed that the systolic and diastolic pressures were less variable in the paced patients than in the control group; the mean hour to hour changes (Table) were similar for systolic pressure with only a small differ- ence for diastolic pressure. Despite the apparently satisfactory paced rhythm, there was considerable beat to beat variability of blood pressure (Fig. 2) mainly as a result of atrioventricular asynchrony but also because of extrasystoles. This was reflected in the diurnal analysis of the beat to beat variability (Fig. 3), which showed that the systolic pressures were more unstable than in the control group. The beat to beat pulse interval was irregular in both groups because of ectopic activity. These effects were sustained over the whole $24 \mathrm{~h}$ period.

\section{PHYSIOLOGICAL TESTING}

Head up tilt-There was a small postural fall in systolic and diastolic pressures; one patient became symptomatic as her blood pressure fell to $93 / 49 \mathrm{~mm}$ Hg (Fig. 4).

Carotid sinus massage-No patient showed a vasodepressor response to vagal stimulation. ${ }^{9}$ As they were all in paced rhythm no changes in the heart rate were seen.

Valsalva manoeuvre-A normal response to the Valsalva manoeuvre for a period of 10 seconds was seen in the control group; there was an initial increase in arterial pressure followed by a fall associated with a reflex tachycardia (Fig. 5). At the end of the manoeuvre there was a pronounced overshoot of systolic pressure, which was absent in the paced group as was the reflex tachycardia.

Cycle ergometry-Only six paced patients were able to perform cycle ergometry, and data for age and sex

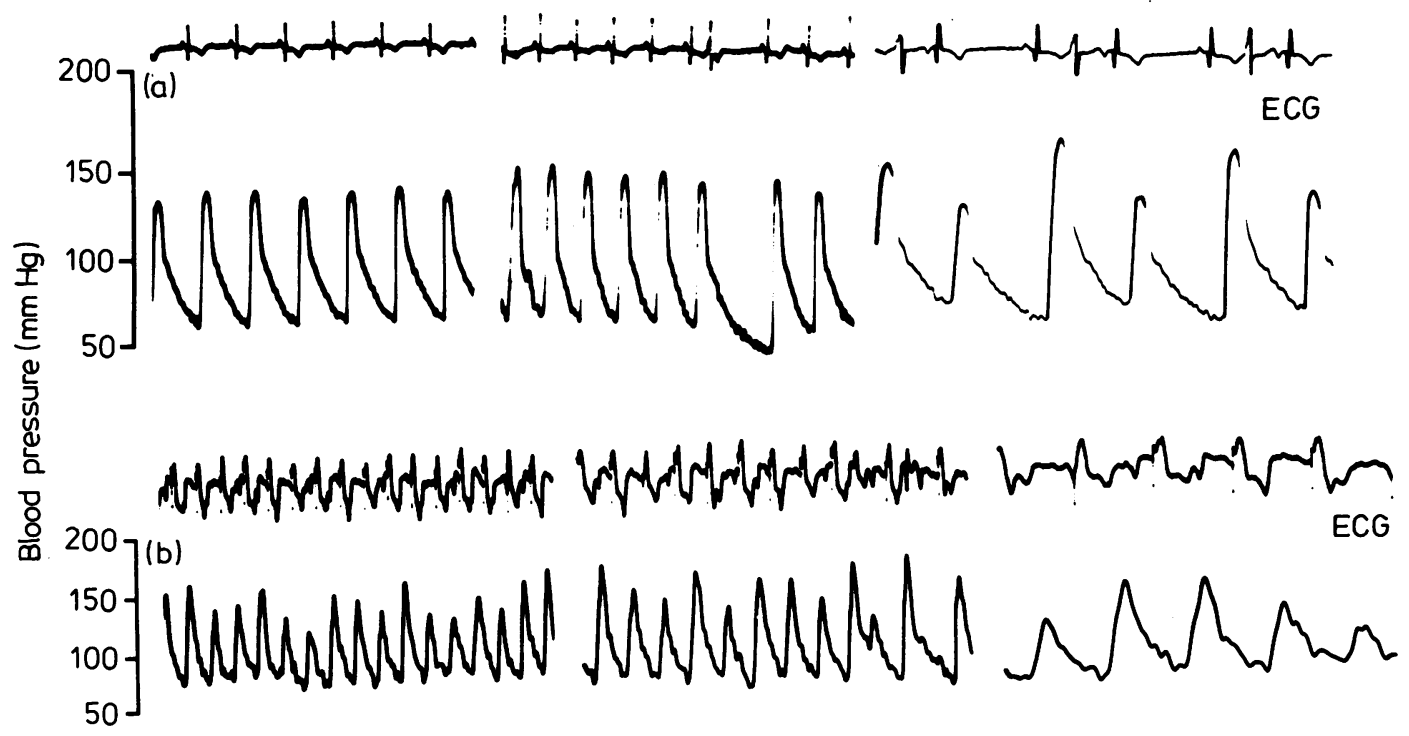

Fig. 2 Examples of blood pressure and electrocardiographic recordings during the ambulant period in (a) a normal control (sinus rhythm) and (b) a paced subject. Pronounced beat to beat fluctuations in pressure are caused by atrioventricular asynchrony and extrasystoles. 


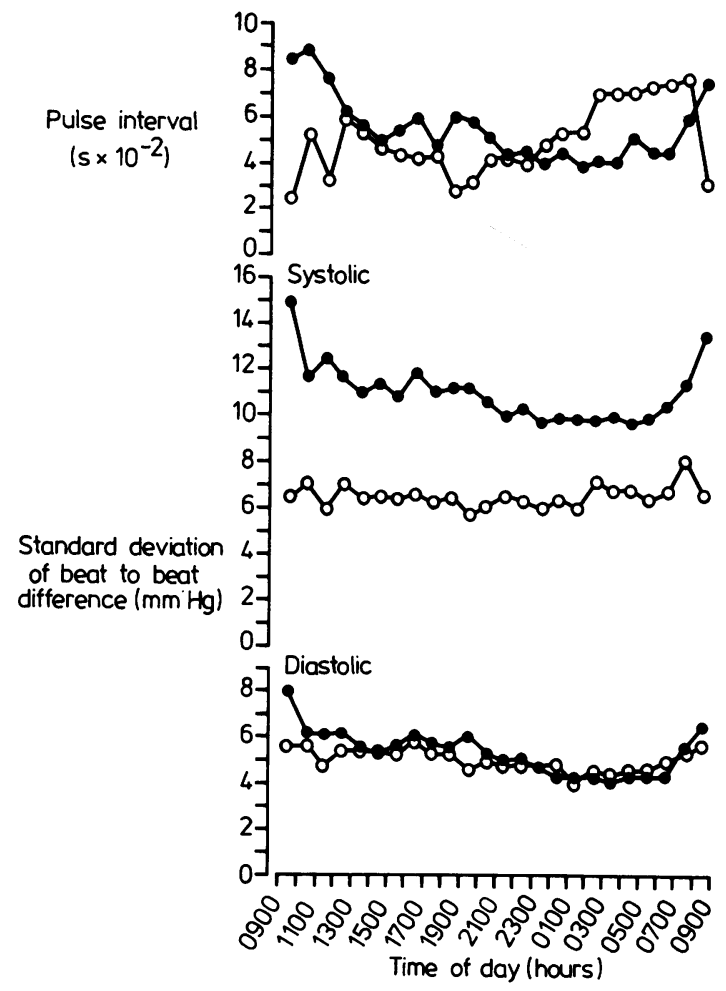

Fig. 3 Beat to beat changes in eight pacemaker patients (O) and eight age matched control subjects $(O)$ plotted as represented by hourly standard deviations. The difference in variability of systolic pressure is pronounced and present throughout the 24 hours.

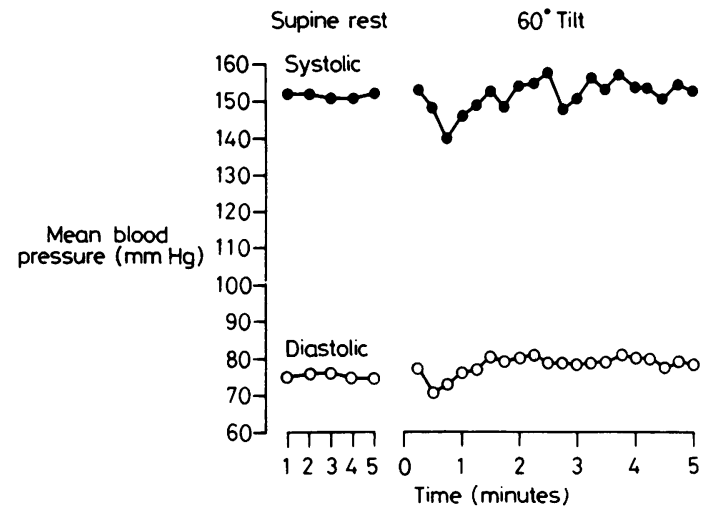

Fig. 4 Effect of $60^{\circ}$ head up tilt on blood pressure in the paced (71 beats/min) patients. Although there was an initial fall in mean pressures, the majority of this can be accounted for by one patient who became symptomatic with a pronounced fall in pressure.

matched patients with hypertension were available for only four (Fig. 6). The heart rate of the paced patients did not rise in response to exercise. The systolic pressure, however, showed a rise on exercise, whereas the diastolic pressure remained unchanged.

\section{Discussion}

The pronounced variability of the blood pressure in both normal and hypertensive subjects has long been appreciated. Millar-Craig $e t a l^{2}$ described a 24 hour circadian pattern of blood pressure and suggested that there may be an internal regulatory mechanism under-

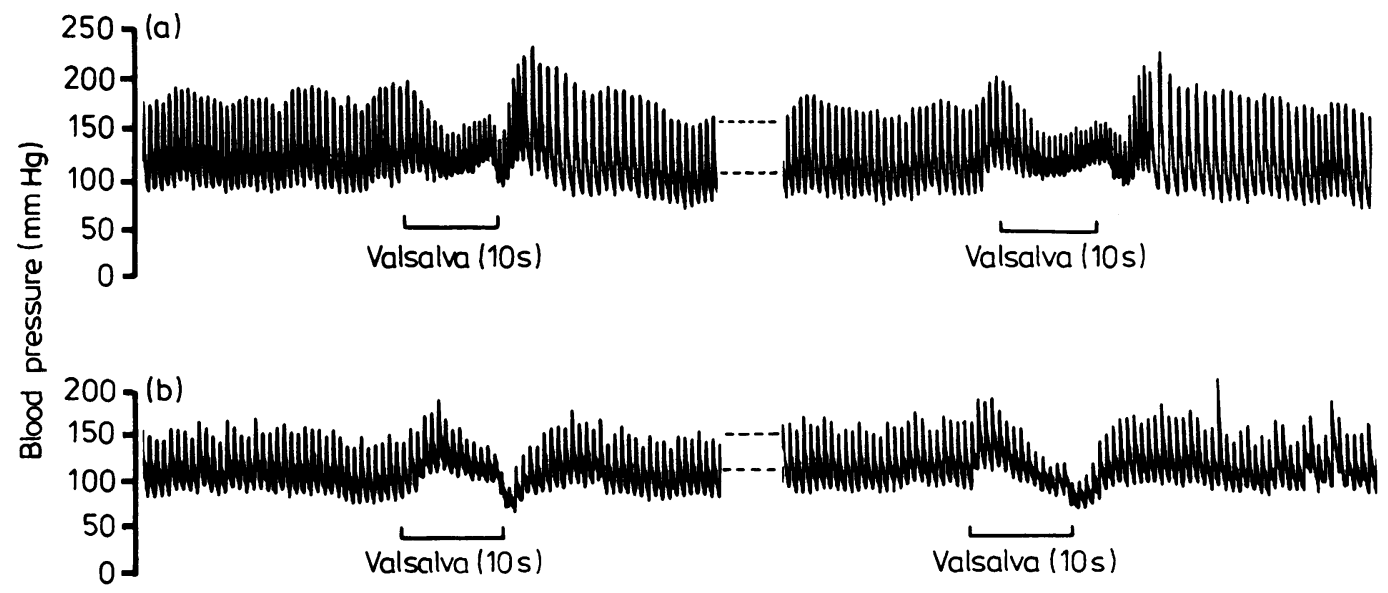

Fig. 5 Blood pressure recordings in (a) a control and (b) a paced subject while performing repeated Valsalva manoeuvres. The paced patient shows a lack of overshoot at the end of breath holding, which was a feature typical of the group. 


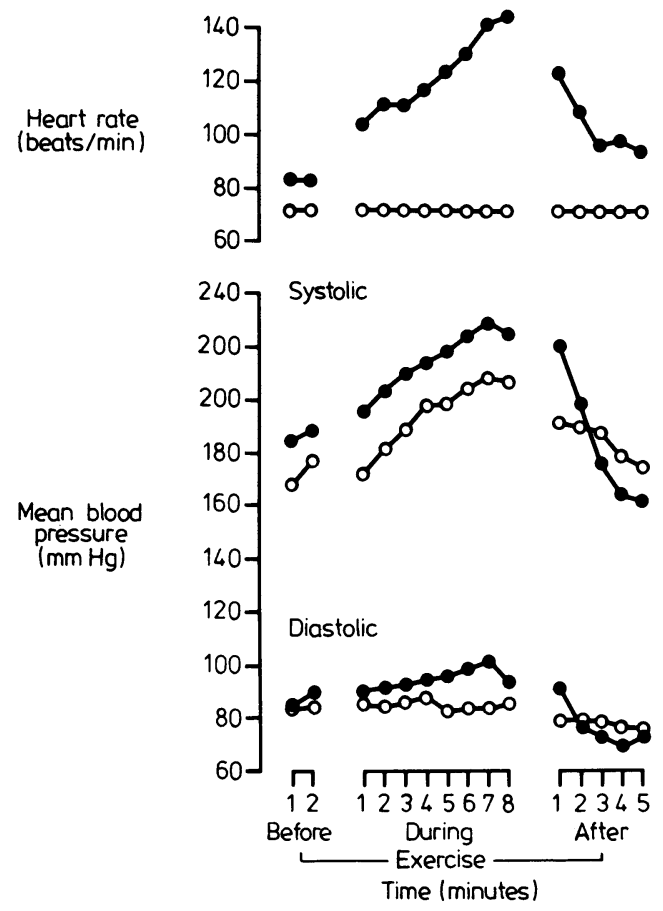

Fig. 6 Response to bicycle ergometry in four paced patients (O) and four age and sex matched control subjects ( () .

lying this pattern; others argued that this merely reflected arousal or heart rate changes. ${ }^{310}$ The data which showed a rise in pressure before awakening were criticised as no allowance had been made for the varying times at which patients awoke, ${ }^{3}$ but normalisation around the time of awakening showed clearly the preawakening rise and that mean heart rate continued to fall until the time of awakening. ${ }^{7}$ Mann $e t$ $a l^{8}$ reported that physical activity makes only a slight difference to the circadian rhythm in that, although the diurnal variation was less pronounced after a day of bed rest, the preawakening rise persisted during a day of controlled activity and bed rest.

In this group of patients we were able to study changes in blood pressure in the absence of changes in heart rate. Activity was not standardised because it appears to have little effect on the overall shape of the circadian curve. ${ }^{8}$ It was particularly interesting to note that the blood pressure in the paced group started to rise two hours earlier than in the control group despite satisfactory sleep reported on the patients' diary cards. The circadian rhythm of blood pressure in the paced patients was still present although considerably "flattened". This could have been caused either by an absence of the normal heart rate response or by a reduced level of physical activity in the paced patients. The control group were not true normal subjects but were hypertensive patients; data on true normal subjects were not available because of the advanced age of the paced group. It has, however, been shown that hypertensive patients have a reduction in day-night differences of blood pressure, ${ }^{9}$ and it was interesting to observe that the blood pressure curve in the paced patients was even more attenuated. It is clear from this data that this was not due to any change in hour to hour variability.

Ventricular demand pacing is known to be haemodynamically inefficient because the contribution of the atrium to the stroke volume is lost. ${ }^{11} 12$ This loss was constant throughout these studies, but it is difficult to envisage that this should have any effect on long term variability. On the other hand, when short term or beat to beat fluctuations were scrutinised, it was clear that this atrioventricular asynchrony was important and was responsible for as much as $50-60 \mathrm{~mm} \mathrm{Hg}$ beat to beat differences in systolic pressure (Fig. 2). This probably reflects the variability of stroke output produced by atrioventricular asynchrony, ${ }^{13}$ but it has been suggested that these blood pressure fluctuations may be caused by a failure of the normal compensatory response of peripheral resistance to a fall in cardiac output perhaps as a result of inappropriate stretching of atrial receptors during ventricular systole.

A similar effect was also produced by ventricular extrasystoles, and it was obviously important to differentiate and quantify both. Recordings of both paced and control groups were further analysed with respect to the electrocardiographic signal by playback on to ultraviolet paper and hand counting of extrasystoles. Only one patient from each group showed a degree of ectopic activity which produced any haemodynamic disturbance ( $>50$ extrasystoles per hour), and these were excluded from a repeated statistical analysis. This showed a reduced pulse interval variability in each group as expected, but the considerable difference in variability of systolic pressures persisted.

In conclusion we found that in a group of patients with a fixed heart rate due to pacemaker dependence the circadian rhythm of the blood pressure persists. This finding lends weight to the suggestion that there are separate autonomic control mechanisms for heart rate and blood pressure.

\section{References}

1 Mann S, Millar-Craig MW, Gould BA, Altman DG, Raftery EB. The assessment of blood pressure variability from hourly mean values. In: Stott FD, Raftery EB, Clement DL, Wright SL, eds. ISAM-GENT 1981 Proceedings of 4 th international symposium on ambulatory 
monitoring. London: Academic Press, 1982: 572-82.

2 Millar-Craig MW, Bishop CN, Raftery EB. Circadian variation of blood pressure. Lancet 1978; i: 795-7.

3 Floras JS, Jones JV, Johnston JA, Brooks DE, Hassan MO, Sleight P. Arousal and the circadian rhythm of blood pressure. Clin Sci Mol Med 1978; 55: 395S-7S.

4 Seldinger SI. Catheter replacement of the needle in percutaneous arteriography. Acta Radiologica 1953; 39: 368-76.

5 Millar-Craig MW, Hawes D, Whittington J. New system for recording ambulatory blood pressure in man. Med Biol Eng Comput 1978; 16: 727-31.

6 Cashman PMM, Stott FD, Millar-Craig MW. Hybrid system for fast data reduction of long term blood pressure recordings. Med Biol Eng Comput 1979; 17: 629-35.

7 Millar-Craig MW. Ambulatory intra-arterial blood pressure in essential hypertension. London University, 1979: 173-253. MD Thesis.

8 Mann S, Millar-Craig MW, Melville D, Altman D,
Cashman P, Raftery EB. The effects of physical activity on the circadian rhythm of blood pressure. In: Stott FD, Raftery EB, Goulding L, eds. ISAM 1979 Proceedings of the 3rd international symposium on ambulatory monitoring. London: Academic Press 1980: 167-76.

9 Weiss S, Baker JP. The carotid sinus reflex in health and disease. Medicine (Baltimore) 1933; 12: 297-354.

10 Rowlands DB, Stallard TJ, Watson RDS, Littler WA. The influence of physical activity on arterial pressure during ambulatory recordings in man. Clin Sci 1980; 58: 115-7.

11 Samet P, Bernstein W, Levine S. Significance of the atrial contribution to ventricular filling. Am $\mathcal{f}$ Cardiol 1965; 15: 195-202.

12 Sowton E. Haemodynamic studies in patients with artificial pacemakers. Br Heart $\mathcal{f}$ 1964; 26: 737-46.

13 Gillespie WJ, Greene DG, Karatzas NB, Lee G de J. Effect of atrial systole on right ventricular stroke output in complete heart block. Br Med F 1967; i: 75-9. 